\title{
Structural and biophysical characterization of HNF-1A as a tool to study MODY3 diabetes variants
}

Laura Kind $^{1 *}$, Arne Raasakka ${ }^{1}$, Janne Molnes ${ }^{2,3}$, Ingvild Aukrust ${ }^{2,3}$, Lise Bjørkhaug ${ }^{4}$, Pål Rasmus Njølstad $^{2,5^{*}}$, Petri Kursula ${ }^{1,6}$ \& Thomas Arnesen ${ }^{1,7,8^{*}}$

\section{Affiliations}

${ }^{1}$ Department of Biomedicine, University of Bergen, Bergen, Norway

${ }^{2}$ Center for Diabetes Research, Department of Clinical Science, University of Bergen, Bergen, Norway ${ }^{3}$ Department of Medical Genetics, Haukeland University Hospital, Bergen, Norway

${ }^{4}$ Department of Safety, Chemistry, and Biomedical Laboratory Sciences, Western Norway University of Applied Sciences, Bergen, Norway

${ }^{5}$ Section of Endocrinology and Metabolism, Children and Youth Clinic, Haukeland University Hospital, Bergen, Norway

${ }^{6}$ Faculty of Biochemistry and Molecular Medicine \& Biocenter Oulu, University of Oulu, Finland

${ }^{7}$ Department of Biological Sciences, University of Bergen, Bergen, Norway

${ }^{8}$ Department of Surgery, Haukeland University Hospital, Bergen, Norway

\section{*Corresponding authors}

Laura Kind (laura.kind@uib.no), Thomas Arnesen (Thomas.arnesen@uib.no), Pål Rasmus Njølstad (Pal.Njolstad@uib.no).

\section{Key words}

$\beta$-cell, biophysics, diabetes, DNA binding protein, HNF-1A, MODY, molecular bases of disease, pancreas, Pit-Oct-Unc protein family, protein folding, protein stability, structure-function relationship, transcription factor 


\begin{abstract}
Hepatocyte nuclear factor 1A (HNF-1A) is a transcription factor expressed in several embryonic and adult tissues, modulating expression of numerous target genes. Pathogenic variants in the HNF1A gene cause maturity-onset diabetes of the young 3 (MODY3 or HNF1A MODY), characterized by dominant inheritance, age of onset before 25-35 years of age, and pancreatic $\beta$-cell dysfunction. A precise diagnosis alters management as insulin can be exchanged with sulfonylurea tablets and genetic counselling differs from polygenic forms of diabetes. More knowledge on mechanisms of HNF-1A function and the level of pathogenicity of the numerous HNF1A variants identified by exome sequencing is required for precise diagnostics. Here, we have structurally and biophysically characterized an HNF1 A protein containing both the DNA binding domain and the dimerization domain. We also present a novel approach to characterize HNF-1A variants. The folding and DNA binding capacity of two established MODY3 HNF-1A variant proteins (P112L, R263C) and one variant of unknown significance (N266S) were determined. All three variants showed reduced functionality compared to the wild-type protein. While the R263C and N266S variants displayed reduced binding to an HNF-1A target promoter, the $\mathrm{P} 112 \mathrm{~L}$ variant was unstable in vitro and in cells. Our results support and mechanistically explain disease causality for all investigated variants and allow for the dissection of structurally unstable and DNA binding defective variants. This points towards structural and biochemical investigation of HNF-1A being a valuable aid in reliable variant classification needed for precision diagnostics and management.
\end{abstract}




\section{Introduction}

Maturity-onset diabetes of the young (MODY) is a monogenic, autosomal-dominant form of diabetes mellitus, which is characterized by impaired $\beta$-cell function and insulin regulation. The disease is caused by mutations in one of 11 genes crucial for pancreatic $\beta$-cell development and homeostasis (1). MODY3, which contributes to $\sim 40-70 \%$ of all MODY cases, is associated with pathogenic variants of the hepatocyte nuclear factor 1A (HNF1A) gene (2). The encoded transcription factor HNF-1A is expressed both in the embryonic and adult stages of the liver, gall bladder, pancreas, gastro-intestinal tract, kidney, urinary bladder, as well as the adult bone marrow and immune system (3). This wide expression pattern of HNF-1A indicates diverse molecular functions in the human body. Specifically in the endocrine pancreas, HNF-1A regulates the expression of numerous target genes involved in glucose regulation and metabolism, such as those encoding the insulin receptor, HNF-4A, the glucose transporter GLUT2, and glucose-6-phosphatase (4-6). In a genome location experiment using human pancreatic islets, HNF-1A was found to occupy promoter regions of 106 islet genes (4) and HNF-1A deficiency in mice resulted in broad changes of islet gene expression patterns (5). Studies on the molecular structure and function of this important transcription factor is likely to improve our understanding of pancreatic islet biology and underlying mechanisms for the development of MODY3.

HNF-1A is a multi-domain protein (Fig. 1A), which contains an N-terminal dimerization domain (DD), a central DNA binding domain (DBD), and a C-terminal transactivation domain (TAD) (3). Three isoforms $(\mathrm{A}, \mathrm{B}, \mathrm{C})$ have been described, which differ in the length of the C-terminal TAD and are differentially expressed in fetal and adult tissues (7). The N-terminal DD is a 32-residue $\alpha$-helical region, which can fold and dimerize independently from the residual domains $(8,9)$. The DD forms a heterotetramer with the pterin-4 alpha-carbinolamine dehydratase 1 (PCBD1), which stabilizes the dimeric form of HNF-1A (10,11). A 50-residue long linker separates the DD from the DBD, which consists of a Pit-Oct-Unc-specific $\left(\mathrm{POU}_{\mathrm{S}}\right)$ domain and a homeodomain $\left(\mathrm{POU}_{\mathrm{H}}\right)$ and can bind to the inverted palindromic consensus DNA sequence GTTAATNATTAAC (12). The 200-residue long DBD contains a nuclear-localization signal (NLS) preceding the $\mathrm{POU}_{\mathrm{H}}$ domain, ensuring translocation of HNF-1A into the nucleus (13). The structure of the isolated $\mathrm{POU}_{\mathrm{H}}$ domain from rat has been solved by $\mathrm{X}$-ray crystallography and nuclear magnetic resonance spectroscopy, revealing an atypical homeodomain with an extended loop between the $\alpha 2$ - and $\alpha 3$-helices $(14,15)$. Chi et al. reported the crystal structure of the entire DBD bound to a high-affinity promoter, corresponding to the consensus sequence for optimal HNF-1A binding (16). The POU $\mathrm{S}_{\mathrm{S}}$ and $\mathrm{POU}_{\mathrm{H}}$ domains form a stable interface when bound to the DNA, potentially increasing affinity and stability of the complex (16). In addition, HNF1A contains a 450-residue long TAD in the C-terminus, which is involved in gene transcription activation and likely interacts with numerous transcription factors, co-activators, and repressors $(13,17,18)$. Apart from structural models for the isolated DD and DBD domains, the HNF-1A protein remains structurally and biophysically uncharacterized.

According to the ClinVar database (19), 418 variants of the HNF1A gene have been reported, out of which 131 are recognized as pathogenic or likely pathogenic. Remaining variants are classified as likely benign, benign, or variants of uncertain significance (VUS). Diabetes-associated missense mutations occur at highest rates in the DBD, while the mutation rate is intermediate in the DD and low in the TAD (16). In this study, we aimed to structurally and functionally characterize the entire DD-DBD HNF-1A region, harboring most of the variants causing MODY3, and to establish the system as a tool to evaluate the dysfunctional characteristics of MODY3-associated variants in vitro. To this end, we compared recombinantly-expressed and purified wild-type (WT) protein and two established pathogenic MODY3 variants: p.Pro112Leu and p.Arg263Cys, hereafter referred to as P112L and R263C (20,21). P112L and R263C, respectively, contribute to approximately 5.7\% and 1.4\% of all MODY3 probands registered in the Norwegian MODY registry to date. Both variants have previously been characterized regarding cellular functions, but molecular mechanisms remain enigmatic $(20,22,23)$. Our biophysical in vitro approach revealed defects regarding protein folding and DNA binding ability, providing explanations for the pathogenicity of these established MODY3 variants. Finally, we used this model system to 
investigate the HNF1A p.Asn266Ser (N266S) variant, which is currently classified as a VUS. N266S is considered as a rare variant, with only one registered proband/family within the Norwegian MODY registry to date. This variant was not described functionally previously, and our biophysical characterizations revealed defects at the protein level, supporting disease causality for the N266S variant. 


\section{Results}

\section{Biophysical and functional characterization of two HNF-1A constructs}

The individual DD and DBD of HNF-1A can be recombinantly expressed and purified for structural studies $(8-10,16)$. In contrast, the C-terminal TAD has not been studied using recombinant expression systems, which is likely due to the disordered nature typical for TADs $(24,25)$. Indeed, using disorder predictions we confirmed that large regions in the TAD have a high tendency for disorder (Fig. 1A). To ensure soluble protein expression, we therefore omitted the TAD in this study and created two HNF-1A constructs: HNF-1A 83-279 contained the isolated DBD, while HNF-1A 1-279 contained the DD, a linker, and the DBD. These constructs are hereafter referred to as HNF-1A DBD and HNF-1A DDDBD, respectively (Fig. 1A).

Both protein constructs were purified to homogeneity. DBD and DD-DBD exhibited a slower SDSPAGE migration than expected based on theoretical molecular weight (Fig. S1); however, the protein identity could be confirmed by peptide mass fingerprinting. Initial dynamic light scattering (DLS) experiments indicated a hydrodynamic radius of approximately $6.0 \mathrm{~nm}$ and $10.7 \mathrm{~nm}$ for construct DBD and DD-DBD, respectively (Fig. 1B). These observations were according to expectations, as construct DD-DBD had a higher theoretical mass than DBD and was expected to be dimeric in solution. Sizeexclusion chromatography coupled to multi-angle light scattering (SEC-MALS) confirmed this result (Fig. 1C), as construct DBD exhibited a molecular weight of $24.0 \pm 2.4 \mathrm{kDa}$ (monomeric theoretical weight: $22.8 \mathrm{kDa}$ ), and construct DD-DBD showed a molecular weight of $61.3 \pm 3.7 \mathrm{kDa}$ (monomeric theoretical weight: $31.2 \mathrm{kDa}$, dimeric theoretical weight: $62.4 \mathrm{kDa}$ ).

Synchrotron radiation circular dichroism (SRCD) measurements were conducted to investigate the secondary structure of DBD and DD-DBD, which adopted an $\alpha$-helical fold. DBD gave a stronger $\alpha-$ helical signal, likely due to the absence of the disordered linker present in the DD-DBD construct (Fig. 1D). These findings were in line with previous reports regarding HNF-1A structure and were important quality-control steps, ensuring that both constructs were suitable for subsequent studies of MODY3 variants.

We qualitatively assessed DNA binding ability of DBD and DD-DBD by electrophoretic mobility shift assays (EMSA), in which the purified proteins were added in different ratios to a double-stranded rat albumin promoter oligonucleotide (RA), and the migration behavior of RA was observed during native gel electrophoresis. As the free oligonucleotide probe migrates faster than when in a macromolecular complex, EMSA allows the separation of bound and unbound oligonucleotide and to approximate binding affinities between a protein and the specific promoter oligonucleotide. EMSA showed that both DBD and DD-DBD bound RA and that the protein:RA complexes differed in size, accordingly to the described size differences of the purified HNF-1A constructs (Fig. 1E). Complex formation started to appear at a molar RA:protein ratio of 1:0.4 and seemed to be nearly complete at a molar ratio of 1:2.

We quantified DNA binding properties by isothermal titration calorimetry (ITC), from which we extracted thermodynamic parameters of complex formation (Fig. 1F,G, Table 2). The stoichiometry values from triplicate measurements were determined to 1.97 for construct DD-DBD and 1.89 for construct DBD (Table 2), which corresponds to a RA:protein binding stoichiometry of 1:2. This observation is in line with the crystal structure of an RA:DBD complex (PDB ID: 1IC8; (16)), in which two DBD molecules bind to one double-stranded RA oligonucleotide. Enthalpy changes $(\Delta H)$ for both constructs were in the same range (Table 2), suggesting a similar binding mechanism. The affinity between the protein and RA was high, as the average equilibrium dissociation constant $K_{D}$ was determined to $100 \mathrm{nM}$ for DD-DBD and $114 \mathrm{nM}$ for DBD (Table 2). EMSA and ITC measurements demonstrated that both constructs were able to bind DNA, establishing them as suitable models for in vitro characterization of disease-causing variants impacting DNA binding. 
A
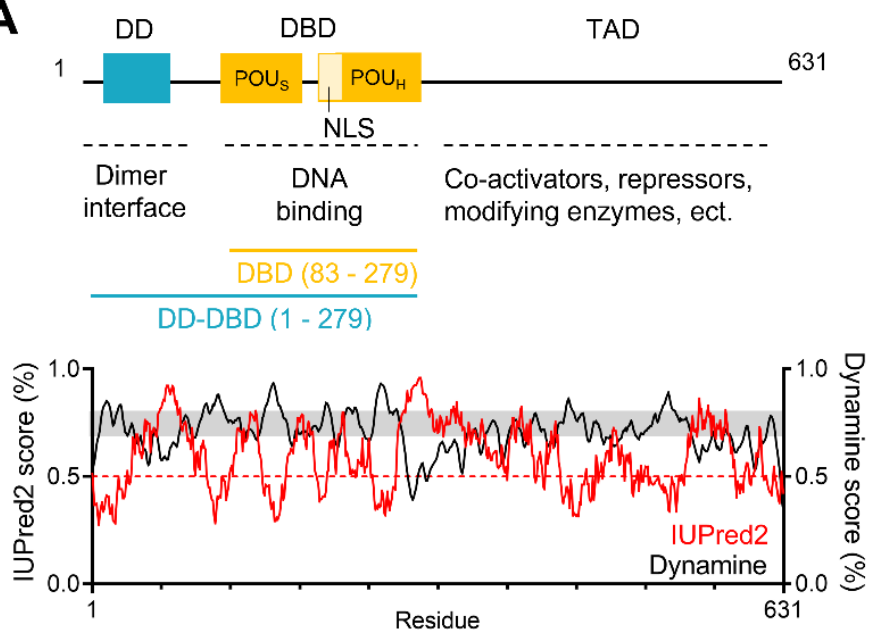

D

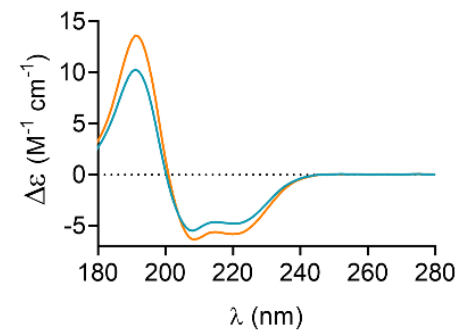

$\mathbf{E}$

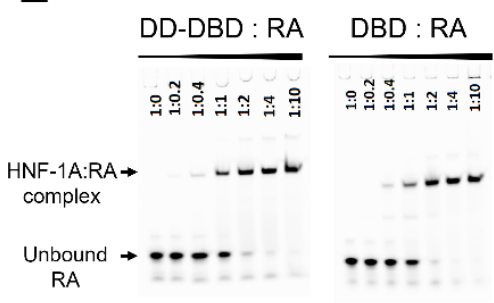

$\mathbf{F}$
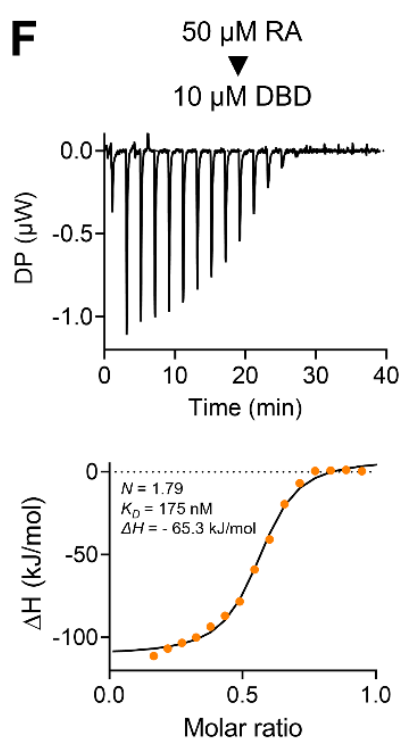

B

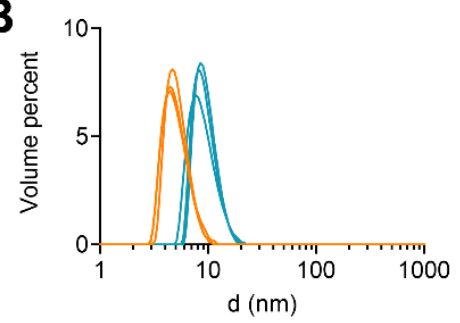

C

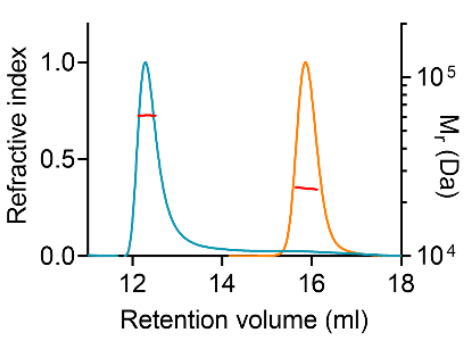

G
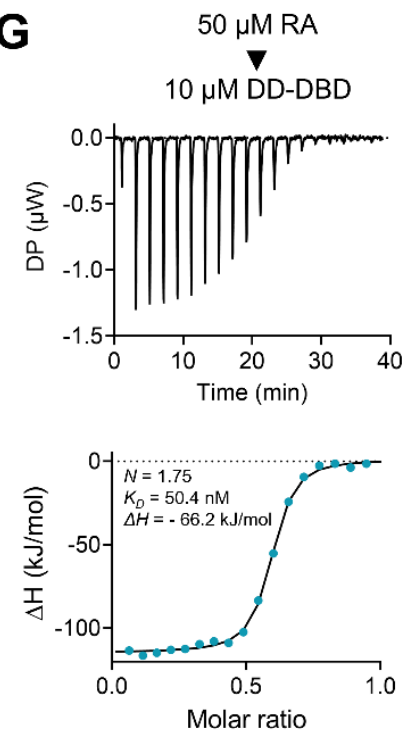

Fig. 1. Biophysical and functional characterization of HNF-1A DBD and DD-DBD constructs. A) Top: Domain overview of HNF-1A with residue numbers and indicated domain functions. DD-DBD (residues 1 - 279) and DBD (residues 83-279) constructs used for in vitro protein characterization are shown in turquois and orange, respectively. Bottom: IUPred2 and DynaMine prediction scores for full-length HNF-1A. IUPred 2 scores above 0.5 indicate propensity for disorder, while scores below 0.5 predict ordered regions (26). DynaMine scores below 0.7 indicate disorder, while scores above 0.8 predict order. DynaMine prediction in the grey zone (scores between 0.7 and 0.8 ) indicate residues with highly context-dependent dynamics (27). B) DLS of DBD and DD-DBD. C) SEC-MALS profiles for DBD and DD-DBD. Red line: molecular weight based on MALS and refractive index. D) SRCD spectra for DBD and DD-DBD. E) EMSA titration native gels showing complex formation of RA and respective HNF-1A construct. F, G) ITC titration curves for DBD and DD-DBD, respectively. Titrant: $50 \mu \mathrm{M}$ double-stranded RA oligonucleotide. Titrand: $10 \mu \mathrm{M}$ DBD (F) or DD-DBD (G). 
bioRxiv preprint doi: https://doi.org/10.1101/2021.12.20.473529; this version posted December 21, 2021. The copyright holder for this preprint (which was not certified by peer review) is the author/funder, who has granted bioRxiv a license to display the preprint in perpetuity. It is made available under aCC-BY-NC-ND 4.0 International license.

\section{HNF-1A DBD and DD-DBD exhibit an extended conformation in solution}

Since both DBD and DD-DBD were predicted to contain flexible linker regions (Fig. 1A), we performed small-angle X-ray scattering (SAXS) to obtain information about the conformation and flexibility of the proteins (Fig. 2). The scattering curves of DBD and DD-DBD gave a first indication that the proteins differ in molecular shape (Fig. 2A). The maximal molecular dimension $\left(D_{\max }\right)$ could be extracted from the distance distribution function (Fig. 2B): $10.2 \mathrm{~nm}$ for DBD and $24.4 \mathrm{~nm}$ for DD-DBD. These results agree with our DLS and SEC-MALS data (Fig. 1B,C). Kratky analysis of the SAXS data showed that both constructs adopt an extended, non-globular conformation, which can be explained by the linkers between the POU $\mathrm{S}_{\mathrm{S}}$ and $\mathrm{POU}_{\mathrm{H}}$ domain, as well as an unfolded region between the DD and DBD (Fig. 2C). Indeed, a CRYSOL analysis, comparing the DNA-bound state of DBD (PDB ID: 1IC8) and the free state in solution, revealed a difference in compactness and overall shape (Fig. 2A). An ab initio model was generated for DBD and superposed with the DBD crystal structure from the DBD:RA complex (16), which illustrates the difference in molecular conformation (Fig. 2D). It appears that the stable interface between the $\mathrm{POU}_{\mathrm{S}}$ and $\mathrm{POU}_{\mathrm{H}}$ domains reported by Chi et al. only forms upon DNA binding. A rigid body model with built linker regions also suggested that the $\mathrm{POU}_{\mathrm{S}}$ and $\mathrm{POU}_{\mathrm{H}}$ domains do not form intimate contacts in the unbound state (Fig. 2E). In order to probe for changes in secondary structure content upon DNA binding, we performed SRCD experiments for both DBD alone and a DBD:RA complex (Fig. 2F). We concluded from the highly similar spectra that there is no notable change in secondary structure content during complex formation, but that the 18-residue linker between the $\mathrm{POU}_{\mathrm{S}}$ and $\mathrm{POU}_{\mathrm{H}}$ domains becomes more compact upon DNA binding. An ab initio model (Fig. 2G) and a rigid body model (Fig. $2 \mathrm{H}$ ) were generated for construct DD-DBD and revealed a similar behavior. The protein adopts an elongated, extended shape in solution.
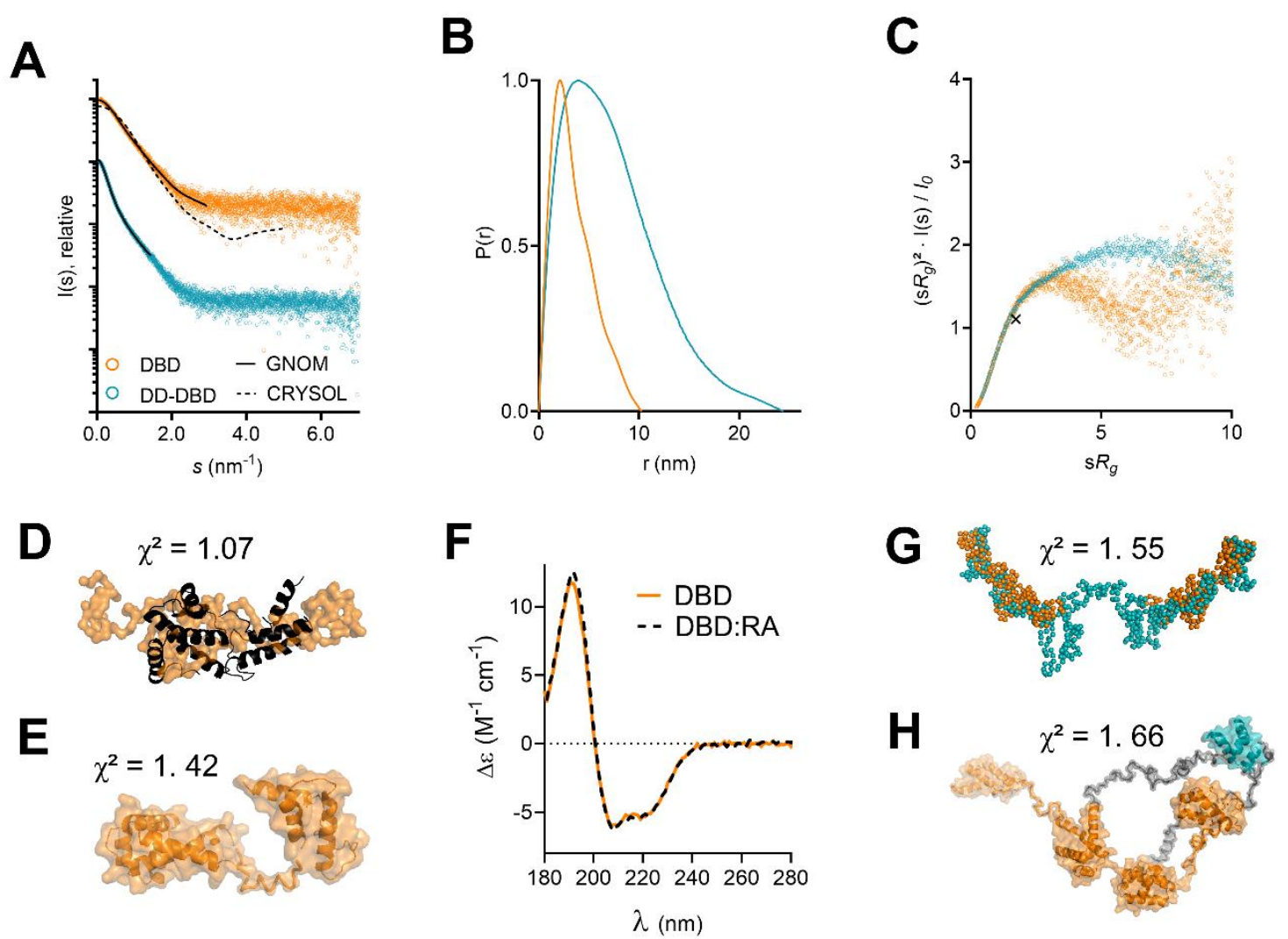

Fig. 2. SAXS data for DBD and DD-DBD. A) Scattering curves for DBD and DD-DBD. Solid line: GNOM fit. Dashed line: CRYSOL fit with crystal structure model from PDB 1IC8 (16) $\left(\chi^{2}=10.4\right)$. B) Distance distribution functions for DBD and DD-DBD. C) Dimensionless Kratky plot for DBD and DD-DBD, with the cross indicating the expected maximum for a globular particle $(\sqrt{3}, 1.104)(28)$. D) GASBOR model of DBD (orange), superposed with the oligo-bound model from DBD:RA crystal structure (16). E) CORAL model for DBD. F) SRCD spectra for DBD in presence and absence of RA. G) GASBOR 
bioRxiv preprint doi: https://doi.org/10.1101/2021.12.20.473529; this version posted December 21, 2021. The copyright holder for this preprint (which was not certified by peer review) is the author/funder, who has granted bioRxiv a license to display the preprint in perpetuity. It is made available under aCC-BY-NC-ND 4.0 International license.

model for DD-DBD (teal), overlaid with GASBOR model of DBD (orange) at estimated positions. H) CORAL model of DDDBD. DBD residues are shown in orange, linker residues in grey, and DD residues in blue.

\section{HNF-1A P112L shows severely reduced solubility in vitro and decreased stability in cells}

Following the biophysical and biochemical characterization of the two HNF-1A WT constructs, we aimed to utilize this system to study diabetes-causing variants of HNF-1A. We chose to explore two established pathogenic variants (P112L and R263C) and one VUS (N266S) to elucidate disease mechanisms of MODY3. All three mutation sites are located in the DBD of HNF-1A (Fig. 3A-D). The alignment of HNF-1A sequences from model organisms (residues 1 - 279) showed that the three affected residues are highly conserved across species down to zebrafish and suggested low tolerance for sequence variance in regard to protein function (Fig. 3A). Pro112 is in the $\mathrm{POU}_{\mathrm{S}}$ domain at the beginning of helix $\alpha 2$ (Fig. 3B,C). Considering the helix-terminating nature of proline residues, this position suggests that Pro112 might have an important role in the secondary structure formation of POU $\mathrm{P}_{\mathrm{S}}$ Both Arg263 and Asn266 are located in the $\mathrm{POU}_{\mathrm{H}}$ domain (Fig. 3B). Both residues are found in the C-terminal helix $\alpha 9$, which is inserted into the major groove of the DNA (Fig. 3D). Arg263 partakes in ionic interactions with the backbone phosphate group of the adenine in the sixteenth position of the RA oligonucleotide (o.A16). In addition, Arg263 forms polar contacts with the backbone carbonyl group of Leu258 and possibly with the side chain of Thr260. Asn266 is situated in proximity of the DNA molecule and may be involved in DNA recognition. The side chain of Asn266 does not partake in direct contacts with other residues, but the polar nature and chain length of asparagine may be important for energetically favorable protein folding.

Initial expression tests in E. coli Rosetta(DE3) distinguished the P112L variant from the R263C and N266S variants. While the latter were equally soluble as the WT constructs, the P112L variant showed a severe reduction in protein solubility (Fig. 3E, Fig. S1A,B). Different lysis buffers were tested, varying $\mathrm{pH}, \mathrm{NaCl}$ concentration, and amounts of stabilizing additives, but no solubilizing condition was found (data not shown). An additional screen in E. coli Lemo21(DE3) was conducted, in which protein expression levels can be tuned by titration of L-rhamnose into the expression media, leading to slower and more controlled protein expression. However, the P112L variant appeared insoluble, independent of the titrant amount (Fig. S1C). This observed insolubility of P112L indicated misfolding of the protein, leading to aggregation or incorporation into bacterial inclusion bodies.

To test the hypothesis of protein instability further, we performed protein turnover experiments in HeLa cells, employing a cycloheximide (CHX) chase assay (Fig. 3F,G, Fig. S2). The drug CHX inhibits protein synthesis in the cells, allowing the assessment of protein degradation dynamics. Using a specific anti-V5 antibody, the amount of full-length V5-WT and V5-P112L protein was detected at different time points of CHX treatment (Fig. 3F). Based on the V5-signal at time point $0 \mathrm{~h}$, it was apparent that the P112L variant is expressed at lower levels than the WT protein at steady state conditions (Fig. 3F). Alternatively, the weaker V5-signals for P112L could arise from lower solubility of the P112L variant as compared to WT HNF-1A. The time-course of normalized protein levels indicated that the protein turnover of the P112L variant was elevated compared to the WT protein (Fig. 3G). 
A

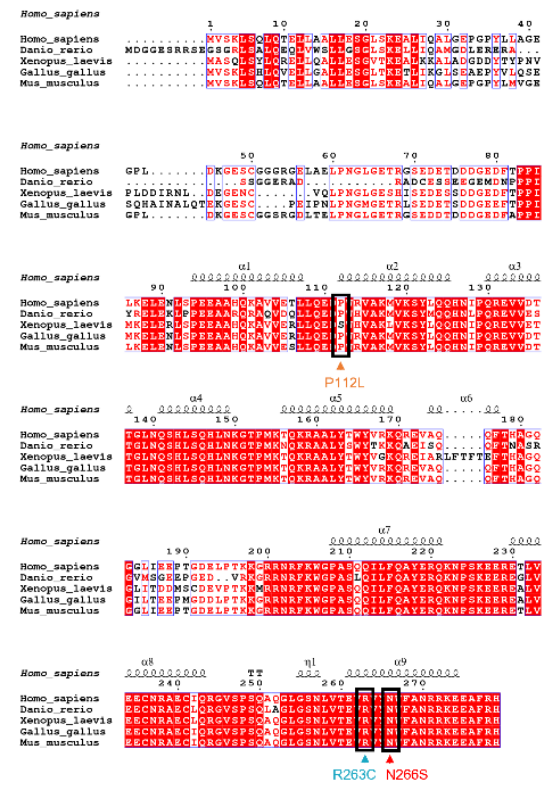

B
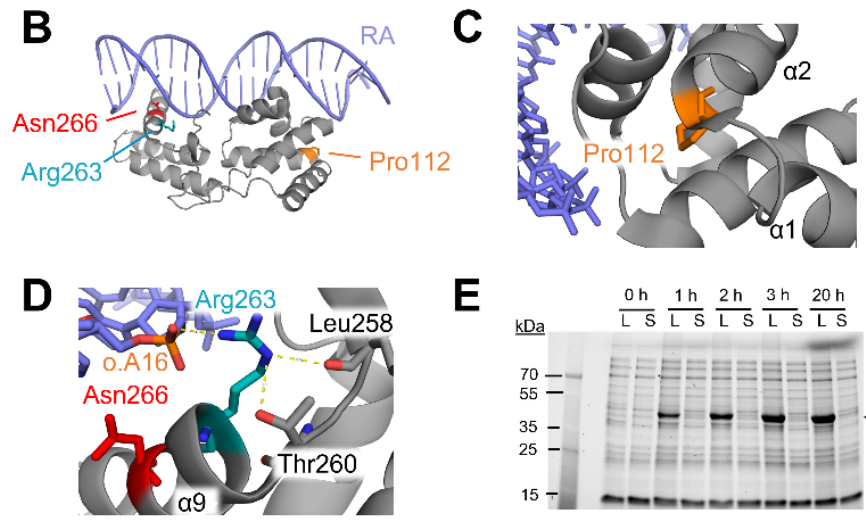

E

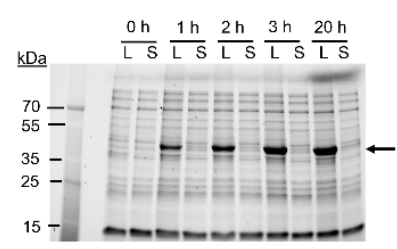

$\mathbf{F}$
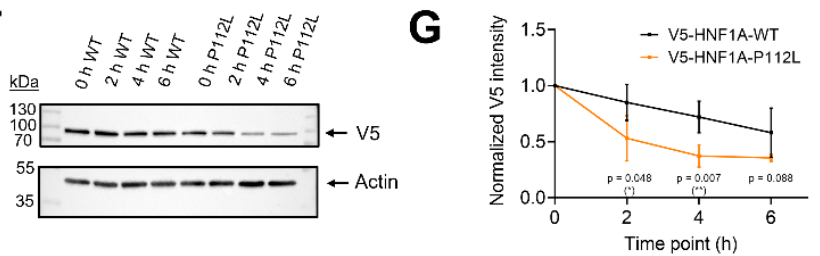

Fig. 3. Overview of the studied variants and protein turnover dynamics of HNF-1A P112L. A) Multiple sequence alignment of HNF-1A sequences from model organisms, with variants of interest indicated by black boxes and arrows. B) Crystal structure of RA-bound DBD (PDB ID: 1IC8) with mutation sites highlighted. C) Magnified view on Pro112 and arrangement of neighboring residues. D) Magnified view on Arg263 and Asn266. o.A16 and neighboring residues Leu258 and Thr260 are indicated. E) Expression and solubility test for DD-DBD P112L (31.2 kDa) in E. coli Rosetta(DE3). Lysate (L) and soluble fraction (S) at different time points of expression $\left(1-3 \mathrm{~h}: 37^{\circ} \mathrm{C}, 20 \mathrm{~h}: 20^{\circ} \mathrm{C}, 0 \mathrm{~h}\right.$ : uninduced control). Arrow indicates over-expressed protein band with an apparent slow migration behavior, as observed for DD-DBD WT. F) Representative western blot membranes of CHX chase assay analysis of full-length WT and P112L protein turnover. G) Quantification of CHX chase assay for HNF-1A WT and P112L, based on normalization to whole protein amount from stain-free SDS-PAGE gel $(\mathrm{N}=4$, Fig. $\mathrm{S} 2)$.

\section{HNF-1A R263C and N266S display normal protein folding and partially altered thermal stability}

The established pathogenic variant R263C and the VUS N266S were expressed and purified like the WT constructs. We performed DLS experiments to investigate hydrodynamic diameters of the proteins and found that the variant constructs were similar to the respective WT constructs (Fig. 4A). SEC-MALS measurements confirmed that $\mathrm{DBD} / \mathrm{R} 263 \mathrm{C}$ was monomeric in solution $\left(\mathrm{M}_{\mathrm{r}}=23.9 \pm 2.4 \mathrm{kDa}\right)$, while DD-DBD/R263C formed a dimer in solution $\left(\mathrm{M}_{\mathrm{r}}=60.2 \pm 3.4 \mathrm{kDa}\right)$ (Fig. 4B, Table S1). The corresponding N266S constructs were found to be in the same oligomeric state (DD-DBD/N266S: $\mathrm{M}_{\mathrm{r}}=$ $61.9 \pm 3.4 \mathrm{kDa}, \mathrm{DBD} / \mathrm{N} 266 \mathrm{~S}: \mathrm{M}_{\mathrm{r}}=24.1 \pm 2.1 \mathrm{kDa}$ ). All variant elution profiles overlapped entirely with the respective WT SEC profile (Fig. 4B).

SRCD spectra of the DBD and DD-DBD variants overlaid with the corresponding WT spectra across the entire wavelength range, indicating identical secondary structure (Fig. 4C). We conducted SAXS experiments to investigate the solution structure of the studied HNF-1A variants (Fig. 4D-F, Table S3). The R263C mutation did not introduce changes in molecular dimension, molecular shape, or flexibility. In contrast, the N266S variant appeared slightly less compact, as a minor increase in $D_{\max }$ (DBD/WT: $10.0 \mathrm{~nm}, \mathrm{DBD} / \mathrm{N} 266 \mathrm{~S}: 11.5 \mathrm{~nm}$ ) became apparent from the distance distribution function (Fig. 4E, Table S3).

Thermal stability was assessed by differential scanning fluorimetry (DSF), from which the melting temperature $\left(T_{M}\right)$ of each variant was extracted (Table 1, Fig. S4). For the WT constructs, the $T_{M}$ values were generally very low (DBD: $42.2^{\circ} \mathrm{C}$, DD-DBD: $35.8^{\circ} \mathrm{C}$ ), which likely results from the presence of the small, separated $\mathrm{POU}_{\mathrm{H}}$ and $\mathrm{POU}_{\mathrm{S}}$ domains, as well as the long, disordered linker in DD-DBD. The DSF protein stability assay also revealed that the (DD-)DBD/R263C variants were as stable as the 
respective WT constructs. In contrast, the N266S mutation was found to de-stabilize the protein during thermal denaturation, as the DBD/N266S variant exhibited a $T_{M}$ value that was $4{ }^{\circ} \mathrm{C}$ lower than the $T_{M}$ of the DBD WT construct (Table 1). The thermal instability of DBD/N266S may be connected to the less compact fold of the same construct, as observed in SAXS.

We compared the experimentally determined stability differences with computational predictions by using the CUPSAT prediction algorithm (Table 1). CUPSAT was used to assess possible changes in free energy of protein folding $(\Delta \Delta G)$ upon point mutation, considering amino acid atom potentials and torsion angle distribution (29). All assessed variants (P112L, R263C, N266S) were predicted to introduce unfavorable torsion angles and to de-stabilize the protein structure $(\Delta \Delta G<0)$, which likely contributes to the observed defects.

A

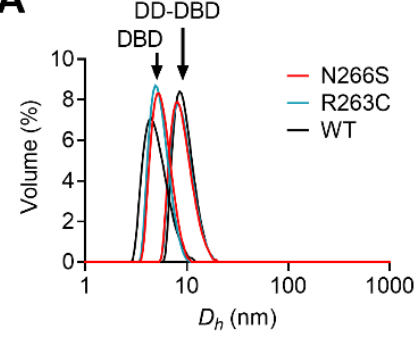

D

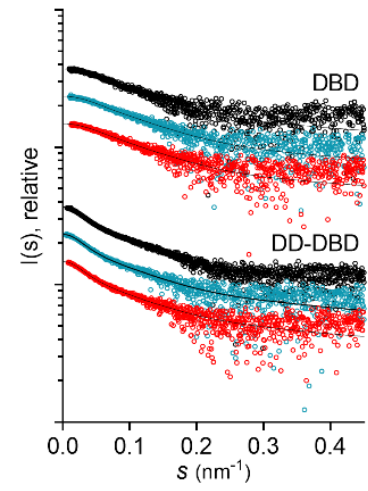

B

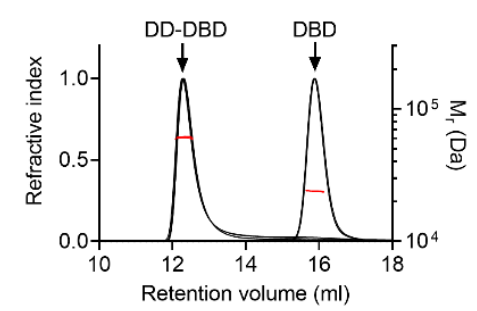

E

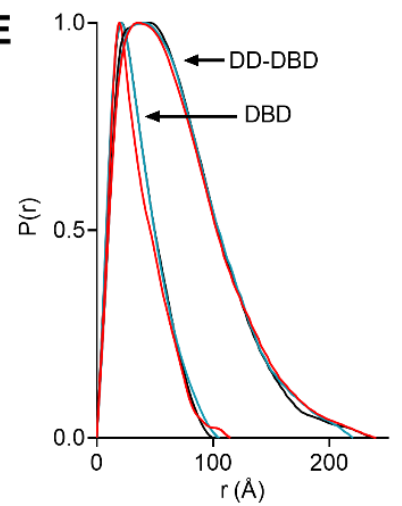

C
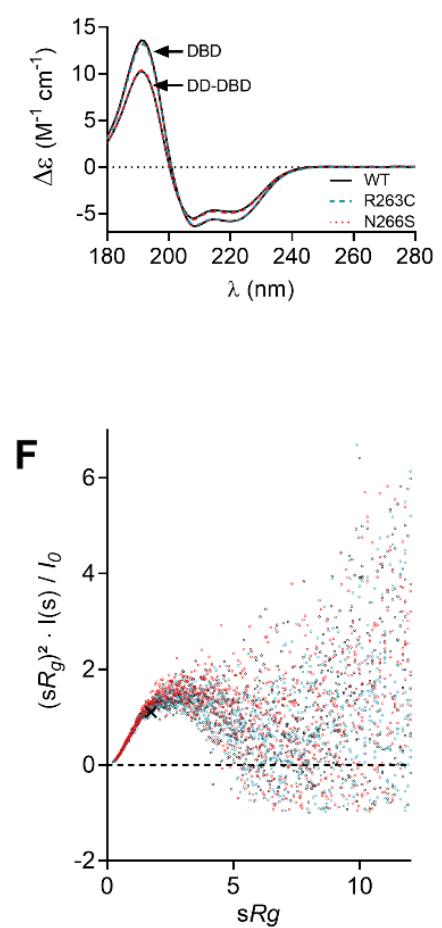

Fig. 4. Biophysical characterization of HNF-1A R263C and N266S. A) DLS curves for DBD and DD-DBD variants. B) SEC-MALS elution profiles for DBD and DD-DBD variants. Red line: molecular weight based on MALS and refractive index. C) SRCD spectra for DBD and DD-DBD variants. D) SAXS scattering curves for DBD and DD-DBD variants. E) SAXS distance distribution functions for DBD and DD-DBD variants. F) Dimensionless Kratky plot for DBD variants, with the cross indicating the expected maximum for a globular particle $(\sqrt{3}, 1.104)(28)$.

Table 1. Thermal protein stability predictions by CUPSAT and experimental $T_{M}$ values determined by DSF analysis (mean \pm SD; $N=4$ ). n.d. - not determined.

\begin{tabular}{|c|c|c|c|c|}
\hline Variant & $\boldsymbol{\Delta} \mathbf{\Delta G}_{\text {CUPSAT }}$ & Torsion $_{\text {CUPSAT }}$ & $\boldsymbol{T}_{\boldsymbol{M}}$ DD-DBD (DSF) & $\boldsymbol{T}_{\boldsymbol{M}}$ DBD (DSF) \\
\hline WT & - & - & $35.8 \pm 0.3^{\circ} \mathrm{C}$ & $42.2 \pm 0.1^{\circ} \mathrm{C}$ \\
\hline P112L & $-1.77 \mathrm{kcal} / \mathrm{mol}$ & Unfavorable & n.d. & n.d. \\
\hline R263C & $-2.5 \mathrm{kcal} / \mathrm{mol}$ & Unfavorable & $36.6 \pm 0.2^{\circ} \mathrm{C}$ & $41.3 \pm 0.1^{\circ} \mathrm{C}$ \\
\hline N266S & $-0.45 \mathrm{kcal} / \mathrm{mol}$ & Unfavorable & $35.1 \pm 0.3{ }^{\circ} \mathrm{C}$ & $38.4 \pm 0.1^{\circ} \mathrm{C}$ \\
\hline
\end{tabular}




\section{HNF-1A R263C and N266S exhibit strongly reduced DNA binding ability}

While the overall folding of R263C and N266S constructs appeared normal, the DNA binding ability was strongly affected (Fig. 5). We performed a dose-dependent EMSA to qualitatively measure DNA binding affinity (Fig. 5A,B). A faint complex band was observed at a 1:0.2 RA:protein molar ratio for WT DD-DBD, while a first complex band for DD-DBD/R263C was only visible at a molar RA:DDDBD/R263C ratio of 1:0.4 (Fig. 5A). Full RA:DD-DBD binding was achieved at a ratio of 1:4, while the $\mathrm{R} 263 \mathrm{C}$ variant did not reach complete binding even at a molar ratio of 1:10. The binding behavior for the R263C variant appeared shifted to the right side of the EMSA titration (Fig. 5A). The EMSA titration for DD-DBD/N266S also revealed a weaker protein DNA complex formation, although not as severe as for DD-DBD/R263C (Fig. 5A,B). A similar behavior was observed in an EMSA titration for the corresponding DBD constructs (Fig. S3). ITC measurements allowed us to quantitatively analyze DNA binding thermodynamics and to precisely compare WT and variant constructs (Fig. 5C-E). Representative titration curves for DD-DBD/R263C and DD-DBD/N266S are shown in Fig. 5C,D. An average $K_{D}$ value of $7.9 \mu \mathrm{M}$ was obtained for DD-DBD/R263C, which is significantly higher than the average $K_{D}$ value of $0.10 \mu \mathrm{M}$ for the DD-DBD WT construct (Fig. 1H, Table 2). DBD/R263C exhibited slightly stronger binding than the dimeric construct, with an average $K_{D}$ value of $1.6 \mu \mathrm{M}$ (Table 2 ). Similar to the WT proteins, the binding event for the R263C variants was an enthalpy-driven process (Fig. 5E). For the N266S variant, ITC experiments revealed average $K_{D}$ values of $0.57 \mu \mathrm{M}$ (DBD/N266S) and $0.74 \mu \mathrm{M}$ (DD-DBD/N266S), which again pointed towards an impaired protein-DNA interaction compared to WT proteins (Fig. 5D,E, Table 2). In addition, the stoichiometry dropped to an average number of approximately 1.6 (Table 2), which suggested a decrease in active protein concentration in the ITC cell. Indeed, a manual inspection of the sample after the ITC experiment confirmed that white precipitation had formed. As the ITC experiment was performed at $30{ }^{\circ} \mathrm{C}$, this aggregation could be explained by the low thermal stability observed in DSF (Table 1).

A

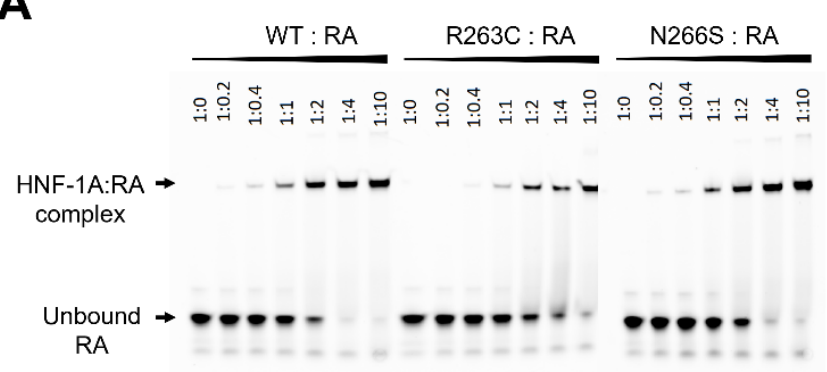

C
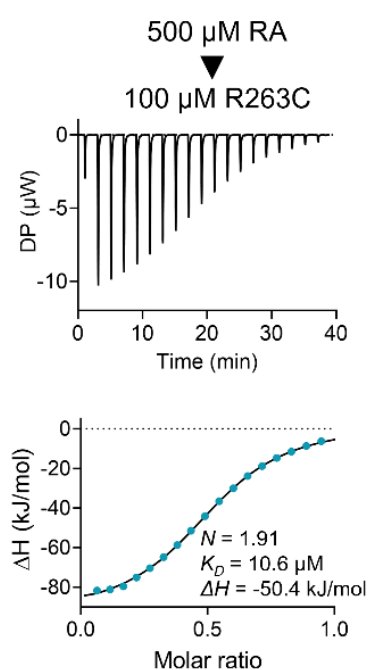

D
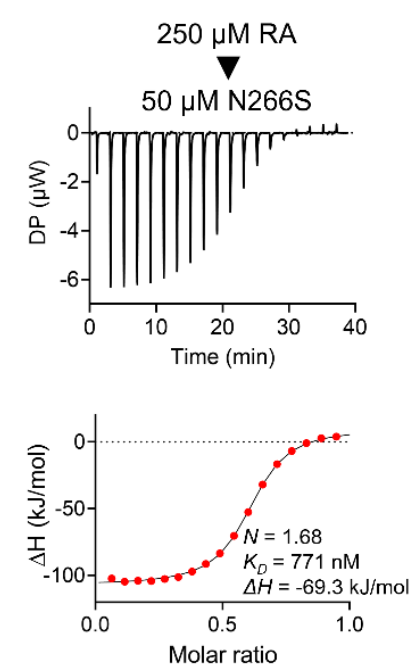

B
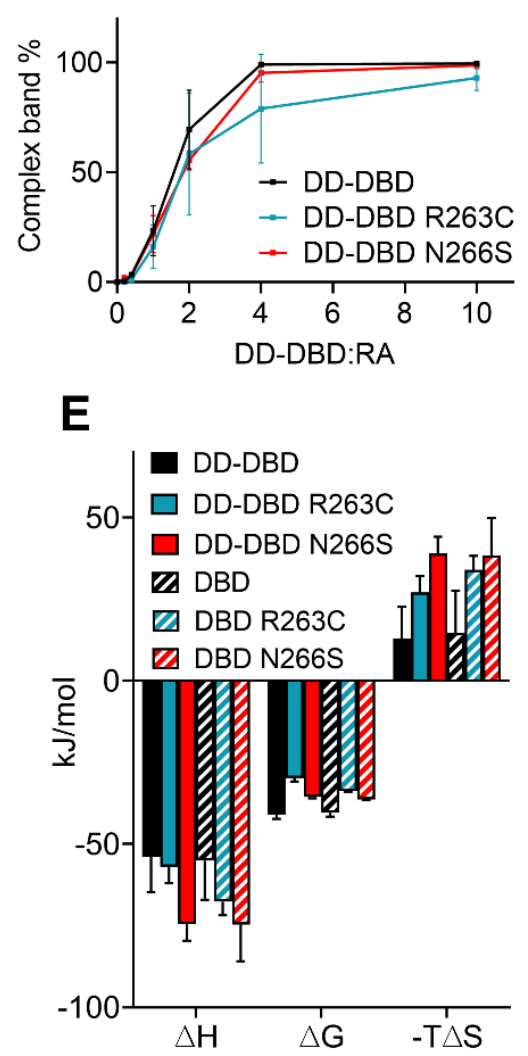
bioRxiv preprint doi: https://doi org/10.1101/2021.12.20.473529; this version posted December 21, 2021. The copyright holder for this preprint (which was not certified by peer review) is the author/funder, who has granted bioRxiv a license to display the preprint in perpetuity. It is made available under aCC-BY-NC-ND 4.0 International license.

Fig. 5. DNA binding parameters for HNF-1A R263C and N266S. A) EMSA gel for DD-DBD WT, R263C, and N266S variants. B) Quantification of EMSA gels for DD-DBD variants $(\mathrm{N}=3)$. C, D) Representative ITC titration curve for DD-

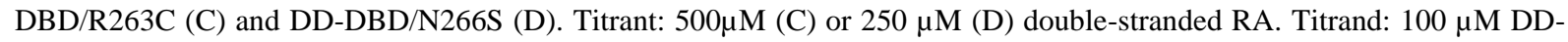
$\mathrm{DBD} / \mathrm{R} 263 \mathrm{C}$ (C) or $50 \mu \mathrm{M}$ DD-DBD/N266S (D). E) Quantification of thermodynamic energies from ITC analysis (mean \pm $\mathrm{SD} ; \mathrm{N}=3)$.

Table 2. Protein:RA $K_{D}$ and $N$ values determined by ITC (mean \pm SD; $\mathbf{N}=3$ ). Parameters were extracted from binding experiments in which double-stranded RA oligonucleotide was titrated into DBD, DD-DBD, or corresponding HNF-1A variant constructs.

\begin{tabular}{|l|l|l|}
\hline HNF-1A construct & $\boldsymbol{K}_{\boldsymbol{D}}(\boldsymbol{\mu M})$ & $\boldsymbol{N}$ (HNF-1A:RA) \\
\hline DBD & $0.10 \pm 0.05$ & $1.89 \pm 0.30$ \\
\hline DBD/R263C & $1.56 \pm 0.14$ & $1.74 \pm 0.09$ \\
\hline DBD/N266S & $0.57 \pm 0.05$ & $1.62 \pm 0.18$ \\
\hline DD-DBD & $0.11 \pm 0.05$ & $1.97 \pm 0.20$ \\
\hline DD-DBD/R263C & $7.87 \pm 3.04$ & $1.73 \pm 0.14$ \\
\hline DD-DBD/N266S & $0.74 \pm 0.11$ & $1.55 \pm 0.11$ \\
\hline
\end{tabular}




\section{Discussion}

Considering the diverse expression patterns and major role of HNF-1A for a functional endocrine pancreas, remarkably little is known about the biochemical structure of HNF-1A and protein function on a molecular level. Notably, pathogenic HNF-1A variants cause the most common form of inherited diabetes, MODY3. Even though the genetic cause of MODY3 is known, there is limited molecular understanding of how a dysfunctional HNF-1A protein leads to decreased insulin secretion. We therefore aimed to extend the knowledge on the structural and biophysical characteristics of HNF-1A to study MODY 3 variants in greater detail. In this work, we henceforth investigated two truncated versions of the HNF-1A protein and three MODY3-associated HNF-1A variants.

Our finding that DD-DBD can dimerize independently of the dimerization co-factors PCBD1 and PCBD2 was expected, as DD had been shown to form homodimers in isolation $(8,9)$. Complex formation with PCBD1/2 may stabilize this dimeric form, as demonstrated by Bayle et al. (11), and thereby modulate HNF-1A function. Even though the DNA binding affinity was not significantly increased for the dimeric construct, the dimerization of HNF-1A may affect the protein's lifetime by protecting it from denaturation and proteolysis (30), or could participate in transcriptional activity as dimerization may increase the local concentration of the regulatory TAD (31).

Moreover, we found that our HNF-1A constructs exhibit a high degree of flexibility. The 30-residue $\mathrm{POU}_{\mathrm{S}}-\mathrm{POU}_{\mathrm{H}}$ linker tethers the two homeodomains together and allows for distance variation between them. This intrinsic conformational flexibility is a general feature of the POU transcription factor family, enabling the proteins to adopt diverse quaternary structures during DNA recognition (32-34). Two wellcharacterized exemplary POU transcription factors are Oct-1 and Pit-1, which are both able to bind to DNA motifs in different arrangements, depending on the nature of the DNA response element (35). Oct1 binds to both the Palindromic Oct-factor response element (PORE) as well as to More of PORE (MORE), albeit in different conformations (36) (Fig. 6). In the PORE binding mode, the POUs and $\mathrm{POU}_{\mathrm{H}}$ domains of one Oct-1 protomer are arranged on opposite sides of the DNA molecule, with the linker being extended across the double helix axis. In contrast, the POU $\mathrm{P}_{\mathrm{S}}$ and $\mathrm{POU}_{\mathrm{H}}$ domains are in a compact formation on the same side of the DNA molecule when Oct-1 is bound to a MORE DNA motif (36). The DNA recognition mode of Oct-1 influences its ability to interact with the transcriptional enhancer OBF-1, which is only able to bind and activate Oct-1 transcriptional activity in the POREbound state $(35,37,38)$. Thus, the conformational flexibility of the Oct-1 transcription factor is crucial for variable arrangements and gene activation modes. A similar conformational variability was shown for the POU transcription factor Pit-1 (39), where different DNA protein arrangements alter the accessibility for transcription modulators, such as the co-repressor N-CoR (35). These examples of protein-DNA recognition modes illustrate the importance of the flexible linker and allow speculations about HNF-1A not only recognizing the established promoters in a MORE-like fashion, but perhaps also binding to undescribed response elements with distinct HNF-1A promoter recognition modes.

MORE

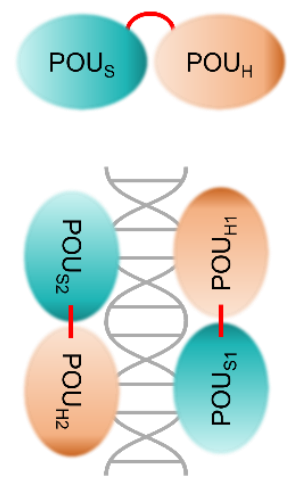

PORE

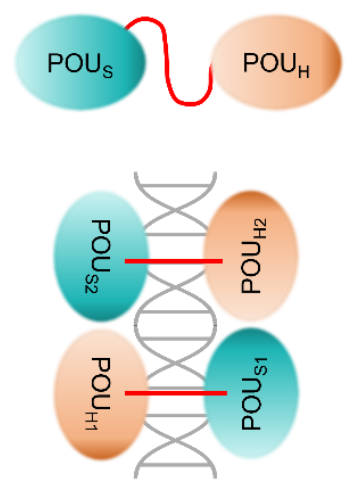

Fig. 6. MORE and PORE DNA binding modes of POU transcription factors (32-36). Transcription factors in MORE arrangement are bound with both

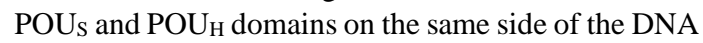
molecule. The homeodomains are in close proximity and the linker is compact. In PORE binding mode, the POU and $\mathrm{POU}_{\mathrm{H}}$ domains are located on opposite sides of the DNA, with the linker being extended across the DNA symmetry axis. 
The P112L variant has previously been functionally studied in cells $(20,22)$. While the nuclear localization appears normal, HNF-1A P112L exhibits strongly impaired DNA binding ability in vitro and transactivation potential on the RA promoter in HeLa cells $(20,22)$. Surprisingly, the P112L constructs were insoluble in our expression conditions. This insolubility could arise from structural instability, which can be explained by the substitution of Pro112 at the critical position in the beginning of helix $\alpha 2$ (Fig. 3B,C). Proline residues play important roles in modulating hydrogen bond formation in $\alpha$-helix backbone structures (40-42), and the P112L substitution may lead to an $\mathrm{N}$-terminally elongated $\alpha 2$ helix with impact on overall protein folding. Moreover, the rigidity and bulkiness of Pro112 may also contribute to protein folding by providing an optimal local backbone conformation.

The conducted protein turnover experiments in HeLa cells support our hypothesis of enhanced protein degradation dynamics. One way to further delineate the mechanism is the application of specific drugs that inhibit lysosomal and proteasomal degradation pathways. Our findings agree with a recent largescale multidimensional analysis of MODY3 variants, where HNF-1A P112L expression in HeLa cells was lower compared to WT HNF-1A (43). Our data supports an alternative cause of disease for HNF1A P112L, with P112L being a structurally destabilizing mutation, rather than a pure DNA binding mutation as suggested in earlier reports $(20,22)$.

HNF-1A R263C proved to be a loss-of-function mutation regarding DNA binding. Our results are in accordance with earlier studies showing that in vitro translated HNF-1A R263C is unable to bind DNA and that this HNF-1A variant has a significantly decreased transactivation potential in HeLa cells $(22,23)$. This effect can be explained by the positioning of Arg263 in HNF-1A (Fig. 3D). Arg263 undergoes direct contacts with o.A16 of the promoter motif and appears to form ion-dipole interactions with Leu258 and Thr260. Interestingly, a genetic variance in the latter (T260M) was identified in a MODY 3 patient. It compromises DNA binding and causes impaired $\beta$-cell function (44). Based on these data, the Arg263-Thr260-Leu258 microenvironment and the direct interaction between Arg263 and o.A16 appear to be crucial for adequate HNF-1A DNA interaction (Fig. 3D).

Finally, we utilized this system to investigate an HNF-1A VUS (N266S), for which previously unknown mechanisms were uncovered. The mutant exhibits altered thermal stability, minor changes in folding, and a decrease in protein:DNA affinity. A combination of all effects may lead to impaired HNF-1A function in the pancreatic $\beta$-cell. Bioinformatic analyses of the protein region harboring the Asn266 residue may assist in explaining possible molecular mechanisms (Fig. S5). By performing a local alignment search for HNF-1A, we identified a homologous protein, Homeobox-containing protein 1 (HMBOX1) (45), which shares $28 \%$ sequence identity and exhibits a conserved homeobox domain (Fig. S5A). A structure alignment between the HNF-1A DBD crystal structure (16) and the crystal structure of the HMBOX1 homeodomain (45) showed high structural similarity between the compared domains (Fig. S5B). Especially the amino acid sequence and structural arrangement of helix $\alpha 9$ is highly conserved between the two proteins (Fig. S5A,B), indicating that residues in this region are critical for HNF-1A and HMBOX1 function. Asn266 in HNF-1A may form polar interactions important for the stabilization of the $\alpha$-helical backbone structure of $\alpha 9$ or might indirectly bind to the DNA. Hence, the N266S substitution may compromise helix stability or DNA binding. Alternatively, the substitution of Asn266 with Ser may potentially introduce a phosphorylation site, which could de-stabilize protein structure and hinder DNA binding. Interestingly, HMBOX1 is strongly expressed in pancreatic tissue, where it may act as a transcriptional repressor (46). The conservation of the homeodomain and the $\alpha 9$ helix in HNF-1A and HMBOX1 allow speculations that both proteins are able to bind to the same target promoter sequence; HNF-1A as a transcriptional activator, and HMBOX1 as a transcriptional repressor. Due to compromised $\alpha 9$ integrity and DNA binding, the N266S variant may be outcompeted by HMBOX1, leading to an altered regulation of gene transcription in $\beta$-cells. Further studies in human cell lines will likely complete our understanding of disease causality, possibly leading to a re-classification of HNF-1A N266S from VUS to (likely) pathogenic.

In summary, we established a biophysical characterization platform for HNF-1A, which proved to be a valuable tool to investigate MODY3 mutations in the DD and DBD of HNF-1A. We verified pathogenic 
effects, as well as provided further understanding for structural and functional dysregulation of the variants. In particular, primary effects caused by structurally de-stabilizing mutations may be uncovered in a direct manner, providing explanations for secondary effects in gene transactivation activity.

\section{Conclusions}

Structural and biochemical studies is an underrepresented approach in the variant interpretation process of transcription factor-associated diseases, such as MODY. Our presented methodology provides new insights into WT HNF-1A protein function, and demonstrates that structure-based investigations may lead to increased certainty in variant-phenotype correlation, and can play a valuable part in MODY precision diagnostics and treatment. 


\section{Experimental procedures}

\section{Plasmid generation}

The human HNF1A gene in a pcDNATM3.1/HisC plasmid (22) was used in order to subclone two HNF1A constructs (DD-DBD: residues 1 - 279, DBD: residues 83 - 279) into the Gateway donor vector pDONR221 (Invitrogen ${ }^{\mathrm{TM}}$ ). An N-terminal Tobacco-Etch Virus (TEV) protease site (ENLYFQG) was included. In addition, attB1 and attB2 sites were introduced $\mathrm{N}$ - and $\mathrm{C}$-terminally of the respective gene fragments, allowing for Gateway cloning strategy. Final expression clones in the destination vector pTH27 (47) harbored an N-terminal His ${ }_{6}$-tag (His $6_{-}(\mathrm{DD}-)$ DBD). MODY3-associated variants (P112L, R263C, N266S) were introduced into (DD-)DBD pTH27 expression plasmids by Q5® site-directed mutagenesis (New England Biolabs, Ipswich, MA, USA). These constructs were used for recombinant protein expression and purification, in order to biophysically and functionally characterize HNF-1A variants.

Using the same strategy, the full-length HNF1A gene sequence (residues 1 - 631) was subcloned into the pcDNA $^{\mathrm{TM}} 3.1 / \mathrm{nV} 5$-DEST mammalian expression vector (Invitrogen ${ }^{\mathrm{TM}}$ ), harboring an $\mathrm{N}$-terminal V5-tag. The P112L variant was generated by Q5® site-directed mutagenesis (New England Biolabs, Ipswich, MA, USA). These constructs were used to assess protein stability in a CHX assay.

Primers used in Gateway cloning, Q5 ${ }^{\circledR}$ site-directed mutagenesis, and plasmid sequencing are listed in table S4.

\section{Recombinant protein expression and purification}

His $_{6}$-(DD-)DBD constructs were expressed in the E. coli Rosetta (DE3). Bacteria were grown in LuriaBertani (LB) medium at $37^{\circ} \mathrm{C}$ until an $\mathrm{OD}_{600}$ value of $0.6-0.8$ was reached. Protein expression, induced by the addition of $1 \mathrm{mM}$ of isopropyl $\beta$-d-1-thiogalactopyranoside (IPTG), was performed at $20^{\circ} \mathrm{C}$ for $20 \mathrm{~h}$.

Bacterial cell pellets were resuspended in $50 \mathrm{mM}$ HEPES (pH 7.5), $500 \mathrm{mM} \mathrm{NaCl}, 1 \mathrm{mM}$ dithiothreitol (DTT), $20 \mathrm{mM}$ imidazole, 1x cOmplete ${ }^{\mathrm{TM}}$ EDTA-free protease inhibitor cocktail (Roche, Basel, Switzerand), $1 \mathrm{mM}$ phenylmethylsulphonyl fluoride (PMSF), and lyzed by ultrasonication (7 min, $1 \mathrm{~s}$ on/off cycles, $25 \mathrm{~W})$. Cell lysates were cleared by centrifugation $\left(16000 \times g, 30 \mathrm{~min}, 4^{\circ} \mathrm{C}\right)$ and $6 x \mathrm{His}-$ (DD-)DBD was purified using Ni-NTA affinity chromatography. Elution was done using an imidazole gradient $(40-300 \mathrm{mM})$ and protein containing fractions were dialyzed overnight at $4{ }^{\circ} \mathrm{C}(20 \mathrm{mM}$ HEPES pH 7.5, $500 \mathrm{mM} \mathrm{NaCl}, 1 \mathrm{mM}$ DTT). The N-terminal His 6 -tags were proteolytically removed by the addition of TEV protease during the dialysis step. A second Ni-NTA affinity chromatography step was used to separate cleaved from uncleaved proteins, where a gradient in a low-imidazole range was applied $(0 \mathrm{mM}-80 \mathrm{mM})$. Relevant fractions were concentrated and subjected to SEC, using a Superdex 75 pg 16/60 column (GE Healthcare, Chicago, IL, USA). The running buffer contained 20 mM HEPES $\mathrm{pH} 7.5,500 \mathrm{mM} \mathrm{NaCl}$, and $1 \mathrm{mM}$ TCEP. Fractions containing pure (DD-)DBD were concentrated, snapfrozen in liquid $\mathrm{N}_{2}$, and stored at $-80^{\circ} \mathrm{C}$.

The expression and solubility of mutant constructs was assessed in E. coli Rosetta (DE3) and E. coli Lemo21 (DE3) strains, varying expression temperatures and lysis buffer composition. HNF-1A variants R263C and N266S were recombinantly expressed and purified in the same way as WT proteins. The HNF-1A P112L variant was not expressed and purified due to insolubility in the tested conditions.

Protein identity was confirmed by peptide mass fingerprinting using a Bruker Ultra fleXtreme MALDI-TOF mass analyzer. 


\section{Dynamic light scattering}

Monodispersity and $\mathrm{R}_{\mathrm{h}}$ of (DD-)DBD variants was assessed using DLS. Measurements of $1.5 \mathrm{mg} / \mathrm{ml}$ purified variants (20 $\mathrm{mM}$ HEPES $\mathrm{pH} 7.5,500 \mathrm{mM} \mathrm{NaCl}, 1 \mathrm{mM}$ TCEP) were performed using a Malvern Zetasizer Nano-ZS instrument at $25^{\circ} \mathrm{C}$. Each variant was measured in triplicate.

\section{Size exclusion chromatography - multi-angle light scattering}

Molecular weights of (DD-)DBD and respective variants were determined using SEC-MALS. Chromatography was performed at room temperature, on a Superdex 200 Increase 10/300GL (GE Healthcare, Chicago, IL, USA) column in SEC buffer (20 mM HEPES pH 7.5, $500 \mathrm{mM} \mathrm{NaCl}, 1 \mathrm{mM}$ TCEP). $100 \mu \mathrm{g}$ sample was subjected to gel electrophoresis at a flow rate of $0.5 \mathrm{ml} / \mathrm{min}$ and MALS was recorded using a miniDAWN TREOS instrument. Concentration determination was based on refractive index, recorded with an on-line ERC RefractoMax 520 refractometer. The monomeric third fibronectin III domain of rat $\beta 4$-integrin ( $\mathrm{MW}=12.76 \mathrm{kDa}$ ) was used as internal molecular weight standard (48). Data were analyzed using the ASTRA software (Wyatt, Santa Barbara, CA, USA).

\section{Differential scanning fluorimetry}

DSF measurements were performed using a Lightcycler 480 II (Roche, Basel, Switzerland) thermocycler. $0.25 \mathrm{mg} / \mathrm{ml}$ DD-DBD or $0.5 \mathrm{mg} / \mathrm{ml}$ DBD variants in $2 \mathrm{mM}$ HEPES $\mathrm{pH} 7.5,50 \mathrm{mM} \mathrm{NaCl}$, $0.1 \mathrm{mM}$ TCEP, $15 \mathrm{x}$ SyproOrange (Invitrogen ${ }^{\mathrm{TM}}$ ) were subjected to thermal denaturation $\left(20\right.$ to $95{ }^{\circ} \mathrm{C}$, $0.2{ }^{\circ} \mathrm{C}$ data pitch). SyproOrange fluorescence at $465-610 \mathrm{~nm}$ was followed. All measurements were performed as technical triplicate. The fluorescence signal was normalized and plotted against temperature. Graphpad Prism 8.3.0 (GraphPad Software, San Diego, CA, USA) was used to fit the data to a sigmoidal function and to extract $T_{M}$ values from the inflection point of the curve.

\section{Small-angle X-ray scattering}

Initial SAXS experiments on WT proteins were performed on the P12 synchrotron beamline (49), EMBL/DESY (Hamburg, Germany), as mail-in service. Batch measurements were done in $20 \mathrm{mM}$ HEPES (pH 8.0), $500 \mathrm{mM} \mathrm{NaCl}, 1 \mathrm{mM}$ TCEP at $10^{\circ} \mathrm{C}$. A dilution series $(0.5 \mathrm{mg} / \mathrm{ml}-2.0 \mathrm{mg} / \mathrm{ml})$ was prepared in order to investigate potential concentration-dependent effects. Bovine serum albumin was used as standard protein for molecular weight determination.

SAXS measurements of all variants were performed as mail-in service on the SWING beamline (50) at the SOLEIL synchrotron (Saint-Aubin, France). All measurements were performed in SEC-SAXS mode using an Agilent Biosec3-300 column at $14{ }^{\circ} \mathrm{C}$ (20 mM HEPES pH 7.5, $500 \mathrm{mM} \mathrm{NaCl}, 2 \mathrm{mM}$ TCEP). $50 \mu \mathrm{l}$ of protein sample at $4-7 \mathrm{mg} / \mathrm{ml}$ was injected, and X-ray scattering data were collected as the sample eluted from the column.

SAXS data were reduced and processed using the ATSAS 3.0.3 package (51). CRYSOL (52) was employed to generate a theoretical scattering curve of the DNA-bound DBD from the published DBD:DNA crystal structure (PDB: 1IC8) (16), which was subsequently compared to the experimental scattering curve of the DNA-free DBD in solution. Ab initio models for (DD-)DBD were generated by using GASBOR (53). Rigid body models of multi-domain proteins were generated by using CORAL (54). Here, the isolated POU $\mathrm{S}_{\mathrm{S}}$ and POU $\mathrm{H}_{\mathrm{H}}$ domains (PDB: 1IC8) and the dimeric DD (PDB: 1F93, (10)) were used as rigid bodies, and linker regions were modelled as flexible loops. Further modelling details are listed in table S2 and S3. Visualization of SAXS models was done in PyMOL (55).

\section{Electrophoretic mobility shift assay}

EMSA was used to qualitatively assess the DNA binding ability of HNF-1A variants. Cy5-labelled oligonucleotide probes, corresponding to the RA promoter as found in PDB 1IC8 (16), were commercially synthesized (Merck KGaA, Darmstadt, Germany) and dissolved in $10 \mathrm{mM}$ Tris pH 8.0, $50 \mathrm{mM} \mathrm{NaCl}, 1 \mathrm{mM}$ EDTA to $100 \mu \mathrm{M}$ final concentration. 5' oligo ([Cy5]- 
CTTGGTTAATAATTCACCAGA) and 3' oligo ([Cy5]-TCTGGTGAATTATTAACCAAG) were mixed in an equimolar ratio. The probes were annealed into double-stranded DNA by incubation at 95 ${ }^{\circ} \mathrm{C}$ for $5 \mathrm{~min}$, before being allowed to cool down to room temperature over $45 \mathrm{~min}$.

EMSA was performed using the LI-COR EMSA buffer kit (LI-COR Biosciences, Lincoln, NE, USA). The EMSA reaction mix contained 1x Binding buffer (10 mM Tris $\mathrm{pH} 7.5,50 \mathrm{mM} \mathrm{KCl}, 1 \mathrm{mM}$ DTT), $0.5 \mu \mathrm{M}$ [Cy5]-RA, $2 \mathrm{mM}$ DTT, and varying amounts of protein sample. The DNA probe was mixed in different ratios with purified (DD-)DBD variants, sampling DNA:protein molar ratios from 1:0 to 1:10. EMSA was performed according to protocol instructions and Cy5 signal was detected from the EMSA gel using a ChemiDoc MP imaging system.

\section{Isothermal titration calorimetry}

ITC measurements were performed using a MicroCal iTC200 instrument (Malvern Panalytical, Malvern, UK). Unlabelled oligonucleotides (TAG Copenhagen, Copenhagen, Denmark) were annealed into double-stranded RA as described above. (DD-)DBD variants and the DNA were dialyzed against $20 \mathrm{mM}$ HEPES pH 7.5, $200 \mathrm{mM} \mathrm{NaCl}, 1 \mathrm{mM}$ TCEP. Typically, $50 \mu \mathrm{M}$ RA was titrated into $10 \mu \mathrm{M}$ (DD-)DBD protein. Higher concentrations were required for the R263C and N266S variants, where 250 $\mu \mathrm{M}$ RA was titrated into $50 \mu \mathrm{M}$ protein. The injection program contained 19 injections with $2 \mu 1$ injection volume, with a two-minute spacing interval. All measurements were performed at $30{ }^{\circ} \mathrm{C}$ in triplicate from the same protein batch. Titrations were analyzed using the MicroCal PEAQ-ITC analysis software (Malvern Panalytical, Malvern, UK). $\Delta H, \Delta G, T \Delta S, K_{D}$, and $N$ were extracted from the fits.

\section{Synchrotron radiation circular dichroism}

SRCD measurements were performed on the AU-CD beamline, ASTRID2 synchrotron, ISA, University of Aarhus, Denmark. Purified proteins and double-stranded RA were dialyzed into CD buffer $(20 \mathrm{mM}$ Na-phosphate buffer pH 8.0, $150 \mathrm{mM} \mathrm{NaF}, 1 \mathrm{mM}$ TCEP). Initial measurements were conducted at 25 ${ }^{\circ} \mathrm{C}$ for WT constructs and HNF-1A:RA complex formation studies. SRCD measurements for the comparison of WT HNF-1A and MODY3 variants were performed at $10{ }^{\circ} \mathrm{C}$. $0.1-\mathrm{mm}$ circular cells (Hellma Analytics, Müllheim, Germany) were used. Initial SRCD spectra on WT constructs and HNF1A:RA complexes were recorded in the wavelength range of $350-170 \mathrm{~nm}$, while spectra for WTvariant comparisons were recorded in a wavelength range of $280-170 \mathrm{~nm}$. Wavelength scans were performed in $1 \mathrm{~nm}$ increments. Three scans per sample were performed and averaged. Generally, protein constructs were measured at a concentration of $1 \mathrm{mg} / \mathrm{ml}$. For measurements of protein:DNA complexes, double-stranded RA oligonucleotide and (DD-)DBD constructs were mixed in a 1:2 molar ratio. Data processing was done using CDtoolX (56) or using Microsoft Excel.

\section{Cycloheximide chase assay}

HeLa cells were grown in DMEM growth medium (Sigma-Aldrich, St. Louis, MO, USA), supplemented with $15 \%$ fetal bovine serum, $1 \%$ penicillin-streptomycin, and $4 \mathrm{mML}$-glutamine, in a humidity incubator keeping constant conditions of $37{ }^{\circ} \mathrm{C}$ and $5 \%$ atmospheric $\mathrm{CO}_{2}$. HeLa cells were seeded in 6well plates at a density of 200000 cells per well. $4 \times 4$ wells were prepared for each variant (WT / P112L HNF-1A). Transfection with full-length nV5-WT or nV5-P112L (0.8 $\mu \mathrm{g}$ DNA/well) was performed $24 \mathrm{~h}$ post-seeding using X-tremeGENETM 9 DNA Transfection Reagent (Roche, Basel, Swityerland). $24 \mathrm{~h}$ post-transfection, the growth medium was exchanged with growth medium supplemented with $50 \mu \mathrm{g} / \mathrm{ml} \mathrm{CHX} \mathrm{(Merck} \mathrm{KGaA,} \mathrm{Darmstadt,} \mathrm{Germany).} \mathrm{Sample} \mathrm{acquisition} \mathrm{was} \mathrm{done}$ at different time points of CHX treatment $(0 \mathrm{~h}, 2 \mathrm{~h}, 4 \mathrm{~h}, 6 \mathrm{~h})$. HeLa cells were washed twice with icecold phosphate-buffered saline (PBS) and harvested in $1 \mathrm{ml}$ ice-cold PBS using a cell scraper. Samples were centrifuged $\left(16000 \times \mathrm{g}, 4^{\circ} \mathrm{C}, 2 \times 15 \mathrm{~s}\right)$ and the dry cell pellets were stored at $-80^{\circ} \mathrm{C}$. Cells were resuspended in $40 \mu 1$ lysis buffer $(50 \mathrm{mM}$ Tris $\mathrm{pH} 8.0,150 \mathrm{mM} \mathrm{NaCl}, 5 \mathrm{mM}$ EDTA, $1 \%$ NP-40, 1x cOmplete ${ }^{\mathrm{TM}}$ EDTA-free protease inhibitor cocktail) and incubated on ice for $30 \mathrm{~min}$. Cell lysates were cleared by centrifugation $\left(16000 \times \mathrm{g}, 10 \mathrm{~min}, 4{ }^{\circ} \mathrm{C}\right)$ and concentrations of the soluble fraction were determined by using the Pierce ${ }^{\mathrm{TM}}$ BCA protein assay (Thermo Fisher Scientific, Waltham, MA, USA). 
bioRxiv preprint doi: https://doi.org/10.1101/2021.1220.473529; this version posted December 21, 2021. The copyright holder for this preprint (which was not certified by peer review) is the author/funder, who has granted bioRxiv a license to display the preprint in perpetuity. It is made available under aCC-BY-NC-ND 4.0 International license.

$20 \mu \mathrm{g}$ protein samples were analyzed by SDS-PAGE and Western blotting. Following protein transfer, the membrane was blocked in 5\% milk-PBS-Tween (milk-PBS-T). Primary antibodies anti-V5 (Invitrogen, R960-25) and anti-pan-actin (Abcam, ab200658) were applied at 1:2000 in 1\% milk-PBS$\mathrm{T}$ and incubated overnight at $4{ }^{\circ} \mathrm{C}$. Membranes were washed three times with PBS-T. Secondary antibody was applied at a 1:5000 dilution in 3\% milk-PBS-T and incubated for $2 \mathrm{~h}$ at $4{ }^{\circ} \mathrm{C}$. Membranes were washed three times in PBS-T before horseradish peroxidase (HRP) signals were developed with SuperSignal ${ }^{\circledR}$ West Pico Chemiluminescent Substrate (Thermo Fisher Scientific, Waltham, MA, USA). Detection of HRP signal was conducted using a ChemiDoc ${ }^{\mathrm{TM}}$ XRS+ imaging system. Band intensities were quantified using the ImageLab ${ }^{\mathrm{TM}}$ v3.0 software (Bio-Rad Laboratories, Hercules, CA, USA). V5bands, representing protein levels of V5-WT and V5-P112L variants, were normalized to total protein amount based on stain-free gel imaging prior to Western blot transfer (Fig. S2). Signals for V5-WT and V5-P112L at different time points of CHX treatment were further normalized to the respective V5-signal at $0 \mathrm{~h}$ treatment. Anti-actin bands were used to visualize equal protein loading. Statistical analysis was done in GraphPad Prism version 8.3.0., using an unpaired t-test per time-point without assuming a consistent SD. Statistical significance was determined using the Holm-Sidak method, with a significance threshold of 0.05 .

\section{Bioinformatic analysis}

Protein disorder prediction was done using the IUPred2 prediction server (26). Prediction score curves produced by IUPred2A and DynaMine (27) algorithms were plotted in Graphpad Prism 8.3.0.

Sequence conservation of the HNF-1A DBD was investigated by the generation of a global alignment. HNF-1A protein sequences from several model organisms were extracted from the UniProt (57) database (Homo sapiens: P20823, Mus musculus: P22361, Danio rerio: Q4L1M9, Xenopus laevis: Q05041, Gallus gallus: Q90867). Sequences were aligned using Clustal Omega (58) and a graphical presentation was generated using ESPript 3.0 (59).

Thermal stability of HNF-1A variants was predicted by using the CUPSAT algorithm (29), considering torsion angle distributions and amino acid atom potentials. As convention, a negative $\Delta \Delta \mathrm{G}$ corresponds to a de-stabilizing point mutation.

A local alignment search for HNF-1A was conducted using the Basic Local Alignment Search Tool (BLAST) (60). A pair-wise alignment of human HNF-1A (UniProt ID: P20823) and human HMBOX1 (UniProt ID: Q6NT76) was generated using Clustal Omega (58) and a graphical presentation was generated using ESPript 3.0 (59). A structure alignment of the DBD of HNF-1A (PDB: 1IC8, chain A, (16)) and the homeobox domain of HMBOX1 (PDB: 4J19, chain A, (45)) was generated with the RCSB PDB pair-wise structure alignment tool using the jFATCAT rigid algorithm (61). Protein structures were analyzed and visualized using PyMOL (55). 


\section{Acknowledgements}

We acknowledge Rezan Erman and Marcus Langeland Larsen Nygård for technical assistance. We are thankful for guidance with SEC-MALS measurements by Dr. Anne Baumann. ITC, DSF, DLS, and SEC-MALS experiments were performed at the Biophysics, Structural Biology and Screening (BiSS) facility at the University of Bergen. We thank Ulrich Bergmann (Biocenter Oulu Proteomics Core Facility) for conducting mass spectrometry analysis. We are grateful for beamtime and supportive synchrotron beamline staff at PETRAIII EMBL P12, SOLEIL Synchrotron SWING, and ASTRID2 ISA AU-CD beamlines.

\section{Funding and additional information}

This work was funded with a PhD fellowship by the Medical Faculty, University of Bergen, UiB, Norway (to L.K.), and supported by a UiB Meltzer foundation project grant (to L.K.). L.K. received a research visit grant from the Norwegian Graduate School in Biocatalysis. T.A. was supported by the Norwegian Cancer Society (Project 171752-PR-2009-0222). P.R.N. received funding from the European Research Council (AdG SELECTionPREDISPOSED \#293574), the Research Council of Norway (FRIPRO grant \#240413), the Western Norway Regional Health Authority (Strategic Fund "Personalized Medicine for Children and Adults"), the Novo Nordisk Foundation (grant \#54741), and the Norwegian Diabetes Association. This work has been supported by the project CALIPSOplus under the Grant Agreement 730872 from the EU Framework Programme for Research and Innovation HORIZON 2020 (to P.K.). 


\section{References}

1. Zhang, H., Colclough, K., Gloyn, A. L., and Pollin, T. I. (2021) Monogenic diabetes: a gateway to precision medicine in diabetes. J Clin Invest 131

2. Yahaya, T. O., and Ufuoma, S. B. (2020) Genetics and Pathophysiology of Maturity-onset Diabetes of the Young (MODY): A Review of Current Trends. Oman Med J 35, e126

3. Lau, H. H., Ng, N. H. J., Loo, L. S. W., Jasmen, J. B., and Teo, A. K. K. (2018) The molecular functions of hepatocyte nuclear factors - In and beyond the liver. J Hepatol 68, 1033-1048

4. Odom, D. T., Zizlsperger, N., Gordon, D. B., Bell, G. W., Rinaldi, N. J., Murray, H. L., Volkert, T. L., Schreiber, J., Rolfe, P. A., Gifford, D. K., Fraenkel, E., Bell, G. I., and Young, R. A. (2004) Control of pancreas and liver gene expression by HNF transcription factors. Science 303, 1378-1381

5. Servitja, J. M., Pignatelli, M., Maestro, M. A., Cardalda, C., Boj, S. F., Lozano, J., Blanco, E., Lafuente, A., McCarthy, M. I., Sumoy, L., Guigo, R., and Ferrer, J. (2009) Hnf1alpha (MODY3) controls tissue-specific transcriptional programs and exerts opposed effects on cell growth in pancreatic islets and liver. Mol Cell Biol 29, 2945-2959

6. Wang, H., Hagenfeldt-Johansson, K., Otten, L. A., Gauthier, B. R., Herrera, P. L., and Wollheim, C. B. (2002) Experimental models of transcription factor-associated maturity-onset diabetes of the young. Diabetes 51 Suppl 3, S333-342

7. Bach, I., and Yaniv, M. (1993) More potent transcriptional activators or a transdominant inhibitor of the HNF1 homeoprotein family are generated by alternative RNA processing. EMBO J 12, 4229-4242

8. De Francesco, R., Pastore, A., Vecchio, G., and Cortese, R. (1991) Circular dichroism study on the conformational stability of the dimerization domain of transcription factor LFB1. Biochemistry 30, 143-147

9. Narayana, N., Phillips, N. B., Hua, Q. X., Jia, W., and Weiss, M. A. (2006) Diabetes mellitus due to misfolding of a beta-cell transcription factor: stereospecific frustration of a Schellman motif in HNF-1alpha. J Mol Biol 362, 414-429

10. Rose, R. B., Bayle, J. H., Endrizzi, J. A., Cronk, J. D., Crabtree, G. R., and Alber, T. (2000) Structural basis of dimerization, coactivator recognition and MODY3 mutations in HNF1alpha. Nat Struct Biol 7, 744-748

11. Bayle, J. H., Randazzo, F., Johnen, G., Kaufman, S., Nagy, A., Rossant, J., and Crabtree, G. R. (2002) Hyperphenylalaninemia and impaired glucose tolerance in mice lacking the bifunctional DCoH gene. J Biol Chem 277, 28884-28891

12. Courtois, G., Baumhueter, S., and Crabtree, G. R. (1988) Purified hepatocyte nuclear factor 1 interacts with a family of hepatocyte-specific promoters. Proc Natl Acad Sci U S A 85, 79377941

13. Bjorkhaug, L., Bratland, A., Njolstad, P. R., and Molven, A. (2005) Functional dissection of the HNF-1alpha transcription factor: a study on nuclear localization and transcriptional activation. DNA Cell Biol 24, 661-669

14. Ceska, T. A., Lamers, M., Monaci, P., Nicosia, A., Cortese, R., and Suck, D. (1993) The Xray structure of an atypical homeodomain present in the rat liver transcription factor LFB1/HNF1 and implications for DNA binding. EMBO J 12, 1805-1810

15. Schott, O., Billeter, M., Leiting, B., Wider, G., and Wuthrich, K. (1997) The NMR solution structure of the non-classical homeodomain from the rat liver LFB1/HNF1 transcription factor. J Mol Biol 267, 673-683

16. Chi, Y. I., Frantz, J. D., Oh, B. C., Hansen, L., Dhe-Paganon, S., and Shoelson, S. E. (2002) Diabetes mutations delineate an atypical POU domain in HNF-1alpha. Mol Cell 10, 11291137

17. Rosenfeld, M. G. (1991) POU-domain transcription factors: pou-er-ful developmental regulators. Genes Dev 5, 897-907

18. Yu, M., Wang, J., Li, W., Yuan, Y. Z., Li, C. Y., Qian, X. H., Xu, W. X., Zhan, Y. Q., and Yang, X. M. (2008) Proteomic screen defines the hepatocyte nuclear factor 1alpha-binding partners and identifies HMGB1 as a new cofactor of HNF1alpha. Nucleic Acids Res 36, 12091219 
19. Landrum, M. J., Lee, J. M., Benson, M., Brown, G. R., Chao, C., Chitipiralla, S., Gu, B., Hart, J., Hoffman, D., Jang, W., Karapetyan, K., Katz, K., Liu, C., Maddipatla, Z., Malheiro, A., McDaniel, K., Ovetsky, M., Riley, G., Zhou, G., Holmes, J. B., Kattman, B. L., and Maglott, D. R. (2018) ClinVar: improving access to variant interpretations and supporting evidence. Nucleic Acids Res 46, D1062-D1067

20. Bjorkhaug, L., Ye, H., Horikawa, Y., Sovik, O., Molven, A., and Njolstad, P. R. (2000) MODY associated with two novel hepatocyte nuclear factor-1alpha loss-of-function mutations (P112L and Q466X). Biochem Biophys Res Commun 279, 792-798

21. Iwasaki, N., Oda, N., Ogata, M., Hara, M., Hinokio, Y., Oda, Y., Yamagata, K., Kanematsu, S., Ohgawara, H., Omori, Y., and Bell, G. I. (1997) Mutations in the hepatocyte nuclear factor-1 alpha/MODY3 gene in Japanese subjects with early- and late-onset NIDDM. Diabetes 46, 1504-1508

22. Bjorkhaug, L., Sagen, J. V., Thorsby, P., Sovik, O., Molven, A., and Njolstad, P. R. (2003) Hepatocyte nuclear factor-1 alpha gene mutations and diabetes in Norway. J Clin Endocrinol Metab 88, 920-931

23. Yang, Q., Yamagata, K., Yamamoto, K., Miyagawa, J., Takeda, J., Iwasaki, N., Iwahashi, H., Yoshiuchi, I., Namba, M., Miyazaki, J., Hanafusa, T., and Matsuzawa, Y. (1999) Structure/function studies of hepatocyte nuclear factor-1alpha, a diabetes-associated transcription factor. Biochem Biophys Res Commun 266, 196-202

24. Staby, L., O'Shea, C., Willemoes, M., Theisen, F., Kragelund, B. B., and Skriver, K. (2017) Eukaryotic transcription factors: paradigms of protein intrinsic disorder. Biochem J 474, 25092532

25. Liu, J., Perumal, N. B., Oldfield, C. J., Su, E. W., Uversky, V. N., and Dunker, A. K. (2006) Intrinsic disorder in transcription factors. Biochemistry 45, 6873-6888

26. Erdos, G., and Dosztanyi, Z. (2020) Analyzing Protein Disorder with IUPred2A. Curr Protoc Bioinformatics 70, e99

27. Cilia, E., Pancsa, R., Tompa, P., Lenaerts, T., and Vranken, W. F. (2014) The DynaMine webserver: predicting protein dynamics from sequence. Nucleic Acids Res 42, W264-270

28. Durand, D., Vives, C., Cannella, D., Perez, J., Pebay-Peyroula, E., Vachette, P., and Fieschi, F. (2010) NADPH oxidase activator p67(phox) behaves in solution as a multidomain protein with semi-flexible linkers. J Struct Biol 169, 45-53

29. Parthiban, V., Gromiha, M. M., and Schomburg, D. (2006) CUPSAT: prediction of protein stability upon point mutations. Nucleic Acids Res 34, W239-242

30. Hashimoto, K., and Panchenko, A. R. (2010) Mechanisms of protein oligomerization, the critical role of insertions and deletions in maintaining different oligomeric states. Proc Natl Acad Sci U S A 107, 20352-20357

31. Frietze, S., and Farnham, P. J. (2011) Transcription factor effector domains. Subcell Biochem 52, 261-277

32. Phillips, K., and Luisi, B. (2000) The virtuoso of versatility: POU proteins that flex to fit. $J$ Mol Biol 302, 1023-1039

33. Malik, V., Zimmer, D., and Jauch, R. (2018) Diversity among POU transcription factors in chromatin recognition and cell fate reprogramming. Cell Mol Life Sci 75, 1587-1612

34. Ryan, A. K., and Rosenfeld, M. G. (1997) POU domain family values: flexibility, partnerships, and developmental codes. Genes Dev 11, 1207-1225

35. Remenyi, A., Tomilin, A., Scholer, H. R., and Wilmanns, M. (2002) Differential activity by DNA-induced quarternary structures of POU transcription factors. Biochem Pharmacol 64, 979-984

36. Remenyi, A., Tomilin, A., Pohl, E., Lins, K., Philippsen, A., Reinbold, R., Scholer, H. R., and Wilmanns, M. (2001) Differential dimer activities of the transcription factor Oct-1 by DNAinduced interface swapping. Mol Cell 8, 569-580

37. Chasman, D., Cepek, K., Sharp, P. A., and Pabo, C. O. (1999) Crystal structure of an OCA-B peptide bound to an Oct-1 POU domain/octamer DNA complex: specific recognition of a protein-DNA interface. Genes Dev 13, 2650-2657

38. Sauter, P., and Matthias, P. (1998) Coactivator OBF-1 makes selective contacts with both the POU-specific domain and the POU homeodomain and acts as a molecular clamp on DNA. Mol Cell Biol 18, 7397-7409 
39. Scully, K. M., Jacobson, E. M., Jepsen, K., Lunyak, V., Viadiu, H., Carriere, C., Rose, D. W., Hooshmand, F., Aggarwal, A. K., and Rosenfeld, M. G. (2000) Allosteric effects of Pit-1 DNA sites on long-term repression in cell type specification. Science 290, 1127-1131

40. Richardson, J. S., and Richardson, D. C. (1988) Amino acid preferences for specific locations at the ends of alpha helices. Science 240, 1648-1652

41. Williams, K. A., and Deber, C. M. (1991) Proline residues in transmembrane helices: structural or dynamic role? Biochemistry 30, 8919-8923

42. Hurley, J. H., Mason, D. A., and Matthews, B. W. (1992) Flexible-geometry conformational energy maps for the amino acid residue preceding a proline. Biopolymers 32, 1443-1446

43. Althari, S., Najmi, L. A., Bennett, A. J., Aukrust, I., Rundle, J. K., Colclough, K., Molnes, J., Kaci, A., Nawaz, S., van der Lugt, T., Hassanali, N., Mahajan, A., Molven, A., Ellard, S., McCarthy, M. I., Bjorkhaug, L., Njolstad, P. R., and Gloyn, A. L. (2020) Unsupervised Clustering of Missense Variants in HNF1A Using Multidimensional Functional Data Aids Clinical Interpretation. Am J Hum Genet 107, 670-682

44. Haliyur, R., Tong, X., Sanyoura, M., Shrestha, S., Lindner, J., Saunders, D. C., Aramandla, R., Poffenberger, G., Redick, S. D., Bottino, R., Prasad, N., Levy, S. E., Blind, R. D., Harlan, D. M., Philipson, L. H., Stein, R. W., Brissova, M., and Powers, A. C. (2019) Human islets expressing HNF1A variant have defective beta cell transcriptional regulatory networks. J Clin Invest 129, 246-251

45. Kappei, D., Butter, F., Benda, C., Scheibe, M., Draskovic, I., Stevense, M., Novo, C. L., Basquin, C., Araki, M., Araki, K., Krastev, D. B., Kittler, R., Jessberger, R., Londono-Vallejo, J. A., Mann, M., and Buchholz, F. (2013) HOT1 is a mammalian direct telomere repeatbinding protein contributing to telomerase recruitment. EMBO J 32, 1681-1701

46. Chen, S., Saiyin, H., Zeng, X., Xi, J., Liu, X., Li, X., and Yu, L. (2006) Isolation and functional analysis of human $\mathrm{HMBOX}$, a homeobox containing protein with transcriptional repressor activity. Cytogenet Genome Res 114, 131-136

47. Hammarstrom, M., Woestenenk, E. A., Hellgren, N., Hard, T., and Berglund, H. (2006) Effect of N-terminal solubility enhancing fusion proteins on yield of purified target protein. J Struct Funct Genomics 7, 1-14

48. Raasakka, A., Linxweiler, H., Brophy, P. J., Sherman, D. L., and Kursula, P. (2019) Direct Binding of the Flexible C-Terminal Segment of Periaxin to beta4 Integrin Suggests a Molecular Basis for CMT4F. Front Mol Neurosci 12, 84

49. Blanchet, C. E., Spilotros, A., Schwemmer, F., Graewert, M. A., Kikhney, A., Jeffries, C. M., Franke, D., Mark, D., Zengerle, R., Cipriani, F., Fiedler, S., Roessle, M., and Svergun, D. I. (2015) Versatile sample environments and automation for biological solution X-ray scattering experiments at the P12 beamline (PETRA III, DESY). J Appl Crystallogr 48, 431-443

50. Thureau, A. R., P.; Pérez, J. (2021) BioSAXS on the SWING beamline at Synchrotron SOLEIL. Journal of Applied Crystallography 54

51. Manalastas-Cantos, K., Konarev, P. V., Hajizadeh, N. R., Kikhney, A. G., Petoukhov, M. V., Molodenskiy, D. S., Panjkovich, A., Mertens, H. D. T., Gruzinov, A., Borges, C., Jeffries, C. M., Svergun, D. I., and Franke, D. (2021) ATSAS 3.0: expanded functionality and new tools for small-angle scattering data analysis. J Appl Crystallogr 54, 343-355

52. Svergun, D. I. B., C.; Koch, M.H.J. (1995) CRYSOL - a Program to Evaluate X-ray Solution Scattering of Biological Macromolecules from Atomic Coordinates. J. Appl. Cryst. 28

53. Svergun, D. I., Petoukhov, M. V., and Koch, M. H. (2001) Determination of domain structure of proteins from X-ray solution scattering. Biophys J 80, 2946-2953

54. Petoukhov, M. V., Franke, D., Shkumatov, A. V., Tria, G., Kikhney, A. G., Gajda, M., Gorba, C., Mertens, H. D., Konarev, P. V., and Svergun, D. I. (2012) New developments in the ATSAS program package for small-angle scattering data analysis. J Appl Crystallogr 45, 342350

55. The PyMOL Molecular Graphics System, Version 1.2r3pre, Schrödinger, LLC.

56. Miles, A. J., and Wallace, B. A. (2018) CDtoolX, a downloadable software package for processing and analyses of circular dichroism spectroscopic data. Protein Sci 27, 1717-1722

57. UniProt, C. (2021) UniProt: the universal protein knowledgebase in 2021. Nucleic Acids Res 49, D480-D489 
58. Madeira, F., Park, Y. M., Lee, J., Buso, N., Gur, T., Madhusoodanan, N., Basutkar, P., Tivey, A. R. N., Potter, S. C., Finn, R. D., and Lopez, R. (2019) The EMBL-EBI search and sequence analysis tools APIs in 2019. Nucleic Acids Res 47, W636-W641

59. Robert, X., and Gouet, P. (2014) Deciphering key features in protein structures with the new ENDscript server. Nucleic Acids Res 42, W320-324

60. Altschul, S. F., Gish, W., Miller, W., Myers, E. W., and Lipman, D. J. (1990) Basic local alignment search tool. J Mol Biol 215, 403-410

61. Prlic, A., Bliven, S., Rose, P. W., Bluhm, W. F., Bizon, C., Godzik, A., and Bourne, P. E. (2010) Pre-calculated protein structure alignments at the RCSB PDB website. Bioinformatics 26, 2983-2985 